\title{
A câmara de nuvens: uma abordagem integrada entre a Física Clássica e a Física Moderna ${ }^{+*}$
}

\author{
Lisiane Araujo Pinheiro ${ }^{1}$ \\ Secretaria de Educação do Estado de Rio Grande do Sul \\ Universidade Feevale \\ Escola de Educação Básica Feevale - Escola de Aplicação \\ Novo Hamburgo - RS
}

\section{Resumo}

O presente artigo apresenta a construção de uma câmara de nuvens $e$ propõe possíveis temas de discussão para a sala de aula de Física do Ensino Médio, utilizando o aparato construído.

Palavras-chave: Câmara de nuvens; Ensino de Física; Radiações ionizantes.

\begin{abstract}
The present paper describes the building of a cloud chamber and possible topics for discussion in Physics high school classes using the apparatus that was constructed.
\end{abstract}

Keywords: Cloud chamber; Physics Teaching; Ionizing radiation.

\section{Introdução}

A câmara de nuvens foi desenvolvida pelo físico Charles Wilson, em 1911, na Universidade de Cambridge. Ao estudar o fenômeno da formação de nuvens na atmosfera, Wilson verificou que íons poderiam servir de núcleos de condensação de vapor d'água supersaturado $^{[1]}$. Ele chegou a esta conclusão observando, em recipientes fechados, que ao expandir o ar ele esfriava e se tornava supersaturado e a umidade condensava-se sobre partículas de pó.

\footnotetext{
${ }^{+}$The cloud chamber: an integrated approach between the Classical Physics and Modern Physics

* Recebido: julho de 2014.

Aceito: abril de 2015.

${ }^{1}$ E-mail: lisi.ap@terra.com.br, lisianeap@feevale.br
} 
Dessa forma imaginou que se um feixe de partículas carregadas atravessasse o recipiente quando ele tinha as condições descritas acima, o vapor super-resfriado se condensaria em gotículas de líquido em torno daquelas partículas ${ }^{[2]}$. O equipamento era composto por um recipiente fechado onde um vapor super-resfriado se condensa em gotículas com a passagem de um feixe de partículas carregadas. Como esta foi a primeira tentativa de construção do equipamento, ele apresentou alguns problemas e posteriormente foi aperfeiçoado. Por este trabalho, Wilson recebeu o Prêmio Nobel de Física em $1927^{2[3]}$.

A câmara de nuvens foi um importante instrumento na investigação da radiação e das partículas elementares ${ }^{[1,4]}$, pois foi o primeiro detector com capacidade de mostrar traços produzidos por partículas subatômicas ${ }^{[1]}$. Foi com o auxílio de uma câmara de nuvens que Anderson detectou o pósitron em $1932^{[3]}$.

Atualmente, mesmo com os grandes detectores de partículas, como CMS (Compact Muon Solenoid) e o ATLAS (A Toroidal LHC Apparatus), entre outros experimentos, que fazem parte do CERN (Organização Europeia para a Pesquisa Nuclear), as câmaras de nuvens ainda são utilizadas, em especial em alguns museus, para que a interação da radiação com a matéria possa ser visualizada.

A história da câmara de nuvens também anda lado a lado com a identificação dos raios cósmicos, feita pelo físico Victor Hess, em 1912. Ao trabalhar com radioatividade Hess observou que eletroscópios carregados de eletricidade se descarregavam sem que se aproximasse qualquer carga elétrica do equipamento. Isso contrariava o que se conhecia, pois estes equipamentos só poderiam se descarregar se cargas elétricas fossem aproximadas deles. Esta observação levou a duas hipóteses; o eletroscópio poderia ter sido atingido por partículas radioativas emitidas por objetos ou pelas paredes do laboratório ${ }^{[5]}$ ou a fonte desta radiação poderia ser a Terra ${ }^{[6]}$. Assim, com o objetivo de explicar porque os eletroscópios se descarregavam, alguns experimentos foram realizados e demonstraram que a velocidade de descarga do equipamento decrescia com o aumento da distância à superfície terrestre, mas estes resultados iniciais foram inconclusivos. Em 1910, um físico suíço chamado Gockel, a bordo de um balão alcançou 4.500 m e apresentou uma conclusão contrária à esperada. Segundo Gockel, os eletroscópios se descarregavam mais rapidamente à medida que se afastavam da superfície da Terra. No entanto, seus instrumentos não eram suficientemente bons para garantir o resultado ${ }^{[7]}$. Então, Hess, a bordo de um balão repetiu o experimento citado, com equipamentos mais eficientes. Munido de uma câmara de ionização ${ }^{3}$, Hess, registrou poucas partículas até uma altitude de 2.000 metros. Acima de 2.000 metros, no entanto, ele registrou um número maior de partículas, e o aumento de partículas foi mais intenso quando o seu balão atingiu a altitude máxima de 5.350 metros. Então, Hess concluiu que este aumento era devido à radiação que entrava na atmosfera a partir do espaço. Para tentar identificar a origem das partículas detec-

\footnotetext{
2 Esse prêmio foi partilhado com Arthur Compton.

3 Dispositivo que registra a passagem de partículas carregadas e de radiação. Seu funcionamento baseia-se na ionização do gás presente no interior da câmara, esse então é atraído por uma placa eletricamente carregada ${ }^{[3]}$.
} 
tadas, Hess, novamente a bordo de um balão e durante um eclipse solar, não encontrou nenhuma variação na ionização identificada anteriormente. A partir disso, concluiu que a radiação vinha de algum lugar que não era o Sol, provavelmente a radiação detectada era proveniente do cosmos. Assim, esse novo tipo de radiação foi chamada de raios cósmicos ${ }^{[6]}$.

Hoje em dia sabemos que grande parte dessa radiação cósmica se origina na Via Láctea $^{[7]}$. Os raios cósmicos, apesar de chamados de raios, são partículas carregadas e muito energéticas que bombardeiam constantemente a Terra. Geralmente são prótons, elétrons, fótons, nêutrons, múons, mésons, etc., mas também podem ser núcleos de maiores dimensões, como os de ferro ${ }^{[5 ; 6]}$. A composição dos raios cósmicos varia com a altitude, ao nível do mar, as partículas que predominam são os múons e elétrons ${ }^{[5]}$. Quando tais partículas atingem a atmosfera terrestre elas criam uma chuva de partículas secundárias de energia mais baixas, e estas podem atingir o solo. A produção da radiação secundária ocorre devido à interação entre os núcleos primários e os átomos da atmosfera terrestre. Particularmente, são formados mésons $\pi^{0}$ e $\eta$ entre outros, que decaem com emissão de fótons e induzem novas cascatas eletromagnéticas. A associação dos dois fenômenos descritos chama-se chuveiros atmosféricos extensos $^{[7]}$. Foi o físico Pierre Auger, em 1938, com o auxílio de câmaras de ionização, contadores Geiger ${ }^{4}$ e câmaras de nuvem, identificou e formação de chuveiros atmosféricos extensos. Eles são formados por raios cósmicos muito energéticos capazes de produzir uma "chuva" de partículas secundárias que se espalham por uma grande área, de até centenas de metros quadrados. Partindo dessa constatação, o Observatório Pierre Auger faz as suas pesquisas no pampa argentino. Com uma área de $300 \mathrm{~km}^{2}$ o observatório se dedica ao estudo de raios cósmicos de alta energia. Estas partículas são extremamente raras e sua origem ainda é desconhecida. O observatório tem obtido dados importantes sobre a direção e a chegada das partículas e a sua interação na atmosfera a energias muito superiores a qualquer energia jamais atingida em laboratório. De fato, cerca de uma centena dessas partículas secundárias passam por nossos corpos a cada segundo ${ }^{[6]}$.

Como dito anteriormente, foi utilizando uma câmara de nuvens na detecção de raios cósmicos, que Carl Anderson, em 1932, identificou a primeira partícula de antimatéria, o pósitron. Hess e Anderson dividiram o Prêmio Nobel de Física em $1936^{[3]}$.

No Brasil, na década de 1930, quando a pesquisa em Física estava começando, o físico Gleb Wataghin reuniu um grupo para estudar os raios cósmicos na recém-criada Universidade de São Paulo (USP) ${ }^{[8]}$. Um dos importantes trabalhos publicados por este grupo foi identificação de chuveiros extensos dentro do túnel da Avenida Nove de Julho, então em construção em São Paulo. Essa observação identificou que estes chuveiros eram capazes de penetrar em grandes quantidades de matéria. César Lattes também fez parte deste grupo ${ }^{[8]}$. As pesquisas de Lattes se deram principalmente registrando a interação dos raios cósmicos com

\footnotetext{
${ }^{4}$ Contador que consiste num cátodo cilíndrico e oco contendo um gás mantido a baixa pressão e num fino ânodo ao longo do eixo do cilindro. Quando uma partícula ou radiação penetra no contador, produz no gás íons e elétrons livres que, acelerados pelo campo elétrico, produzirão outros íons e elétrons livres; esses, capturados pelo ânodo, geram um impulso elétrico ${ }^{[3]}$.
} 
emulsões fotográficas em altas altitudes ${ }^{[1]}$. Por indicação do físico italiano Giuseppe Occhialini, seu amigo e professor, Lattes ingressou no grupo de pesquisas do laboratório $\mathrm{H}$. H. Wills Physical Laboratory, da Universidade de Bristol, liderado pelo físico inglês Cecil Powell ${ }^{[8]}$. Os experimentos realizados por Lattes se baseavam em expor chapas fotográficas muito sensíveis, no monte Chacaltaya, na Bolívia, que tem cerca de 5.600 m. Após a exposição, a análise das chapas fotográficas era feita no laboratório citado. Lattes concluiu que quando os raios cósmicos colidiam com núcleos de oxigênio e nitrogênio presentes na atmosfera, produziam dois tipos de mésons ${ }^{5}$, o méson $\pi$ (hoje, píon) e o méson $\mu$ (hoje, múon). Assim, em 1947, o méson $\pi$ foi identificado. Os mésons $\pi$ eram formados em grandes altitudes e os mésons $\mu$, ao nível do mar. Também foi detectado que o mésons $\mu$ era um produto do decaimento do méson $\pi$. Esse trabalho rendeu ao grupo liderado por Powell o Prêmio Nobel de Física de $1950^{[3]}$.

\section{Materiais utilizados e procedimentos de construção da câmara de nuvens}

Esta pode ser uma atividade muito atrativa aos estudantes, em especial aos do Ensino Médio. A construção de uma câmara de nuvens é viável mesmo para um orçamento de uma escola pública. Abaixo, descrevem-se os passos da construção que foi proposta, primeiramente, na Escola de Professores de Língua Portuguesa do CERN 2013 ${ }^{[9]}$, e concretizada, posteriormente, no V Encontro Estadual de Ensino de Física do Rio Grande do Sul, em outubro de 2013, na oficina Conhecendo o CERN: oportunidades para professores de Física, ministrada pelos professores Lisiane Araujo Pinheiro e Maurício Girard, ambos participantes da Escola de Física do CERN 2013. Também são apresentados materiais e procedimentos alternativos para a construção do aparato experimental ${ }^{[9]}$.

Sugere-se que a construção da câmara de nuvens comece pela escolha de caixa de acrílico ou vidro (um aquário, por exemplo) transparente com aproximadamente $20 \times 30 \mathrm{~cm}$ (com a base aberta) x $15 \mathrm{~cm}$ (altura). São as medidas da caixa que determinarão as dimensões de todo o aparato experimental. Mas também é possível utilizar um vidro de conserva ou até um copo plástico, opte por materiais que tenham uma boa transparência para a visualização das interações. Em ambos os casos, procure objetos com a maior circunferência possível.

Também será usada uma placa preta metálica com pelo menos $5 \mathrm{~mm}$ de espessura, que pode ser substituída por uma forma de alumínio ${ }^{6}$ com as dimensões um pouco maiores as da caixa transparente, pois a placa metálica deve cobrir completamente a abertura da caixa citada. A cor preta da placa justifica-se por propiciar uma visualização mais perceptível das interações. O projeto original, apresentado na Escola de Professores de Língua Portuguesa do CERN 2013, a placa tem um sulco na sua volta, no qual a abertura da caixa deve coincidir. O seu papel é de propiciar um bom encaixe entre a placa e a caixa, além de ser o local no qual

\footnotetext{
5 Partícula subatômica formada por um quark e um antiquark.

${ }^{6} \mathrm{O}$ alumínio apresenta uma boa condutividade térmica.
} 
depositaremos o álcool isopropílico . Para fazer o sulco sugere-se uma usinagem. Essa usinagem deve aprofundar $1,5 \mathrm{~mm}$ a placa de alumínio, com largura um pouco superior à espessura das faces da caixa, de forma que seja possível mover levemente a caixa no sulco da placa. Se não for possível fazer a usinagem é possível fazer o sulco utilizando fita isolante.

Uma folha de feltro (aproximadamente $0,3 \mathrm{~mm}$ de espessura), que será fixada no fundo da caixa, vidro de conserva ou copo plástico, cobrindo 3/4 desta área. Ao fazer a fixação do feltro é necessário centraliza-lo. Para fixá-lo é possível utilizar uma fita dupla face ou colchetes para arquivos (nesse caso, será necessário furar a caixa).

Uma caixa de madeira que deve ter uma área um pouco maior do que a placa de metal e ter cerca de $5 \mathrm{~cm}$ de altura. Isopor (aproximadamente com $1 \mathrm{~cm}$ de espessura) e papel alumínio, ambos em quantidade suficiente para forrar a caixa de madeira. Também utilizaremos uma lanterna, fundamental para visualizarmos as interações.

Álcool isopropílico $(100 \mathrm{ml})$ e gelo seco $(0,5 \mathrm{~kg})$, quantidades suficientes para a realização do experimento uma vez, mas se optar pelo uso de um vidro de conserva ou copo plástico, a quantidade de álcool isopropílico pode ser reduzida para $50 \mathrm{ml}$. O gelo seco pode ser comprado em produtoras de festas. Luvas para manusear o gelo seco (luvas de couro) e o álcool (luvas de látex).

No fundo da caixa de madeira, coloque o isopor e cubra com uma folha de papel alumínio. Após, coloque o gelo seco sobre o papel alumínio.

O próximo passo é colocar a placa metálica sobre o gelo seco. Umedeça o feltro e preencha o sulco da placa metálica com o álcool isopropílico. Em seguida coloque a caixa transparente em cima da placa de alumínio. É necessário encaixar a borda da caixa no sulco da placa. Uma boa vedação garante o bom funcionamento da câmara.

Ao utilizar os materiais alternativos, sugere-se que na forma de alumínio seja feito o sulco, de acordo com as dimensões do material utilizado, com fita isolante, no qual será colocado o álcool. Umedeça o feltro e coloque o recipiente em cima da forma.

Mais detalhes sobre a construção da câmara de nuvens estão disponíveis no vídeo Câmara de nuvens para detectar partículas cósmicas .

\section{O que é possível observar na câmara de nuvens?}

Todo tipo de radiação ionizante que chegar até ela. Como dito anteriormente, somos bombardeados constantemente por raios cósmicos, uma radiação invisível e inofensiva. Considerando os raios cósmicos, as partículas que podem ser detectadas ao nível do mar, são os elétrons e os múons ${ }^{[5]}$. Além disso, também interagimos com a radiação natural existente na

\footnotetext{
${ }^{7} \mathrm{O}$ álcool etílico também pode ser usado, mas recomenda-se o uso do álcool isopropílico pela sua pureza. Com uma menor quantidade de água evita-se a formação de cristais de gelo. Assim, um líquido relativamente puro apresenta uma boa capacidade de evaporação à temperatura ambiente.

${ }^{8}$ Disponível em: <http://www.youtube.com/watch?v=KsPIFFEiCc8>. Acesso em: 01 mar. 2015.
} 
Terra. Desde a constituição do Universo que átomos radioativos se desintegram, a maior parte deles decai ${ }^{9}$ até atingir a estabilidade. O decaimento depende do tempo de meia-vida ${ }^{10}$, alguns átomos continuam radioativos por terem uma meia-vida muito elevada. Um exemplo é o urânio-235 que tem uma meia-vida de 713 milhões de anos ${ }^{[10]}$. As fontes de radiação natural são o solo, a água e o ar, pois todos os elementos radioativos naturais encontram-se presentes, em pequenas proporções, nesses materiais. No ar, a concentração de gás radioativo radônio, aumenta em qualquer ambiente fechado, com pouca renovação de ar. O gás radônio também emana da areia utilizada em construções.

Após a montagem da câmara, escureça a sala e espere alguns segundos para que a câmara alcance o estado de equilíbrio e seja possível ver os primeiros rastros. Para observar melhor a interação da radiação com a matéria, aponte a lanterna para a nuvem de vapor de álcool que se formará próxima à placa preta. É olhando para a placa que você verá os rastros deixados pelas interações (Fig. 1).

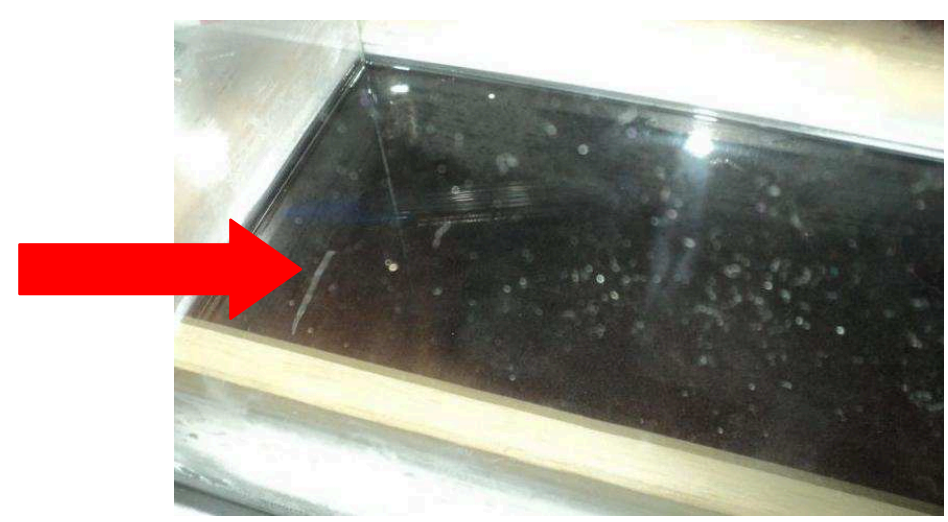

Fig. 1 - Identificação, seta vermelha, de um evento de interação da radiação com a matéria. Foto: Prof. Edilson Torma.

\section{Como a câmara funciona?}

O álcool contido no feltro evapora, e desce lentamente em direção à placa metálica, preenchendo toda caixa. Como temos muito álcool no sistema, a câmara vai se saturando de vapor de álcool. O vapor mais próximo à placa metálica se resfria. Ao se resfriar a densidade do vapor aumenta e ele se condensa sobre a placa. Esse processo dá inicio a um ciclo de convecção, onde o álcool está constantemente evaporando do feltro na parte superior da câmara e se condensando sobre a placa metálica na parte inferior ${ }^{[9]}$.

Quando uma partícula carregada atravessar esse sistema, ela ionizará o vapor supersaturado de álcool. A ionização induz a condensação das gotículas de álcool, formando os

\footnotetext{
${ }^{9}$ Transformação espontânea de um nuclídeo ou de um núcleo composto em outro, sendo que estes, no decorrer do processo, emitem partículas como fótons, elétrons e neutrinos. Ocorre também para uma dada amostra radioativa a diminuição de sua atividade nuclear ${ }^{[1]}$.

10 Tempo necessário para a atividade de um elemento radioativo ser reduzida à metade da atividade inicial.
} 
rastros mostrados na Fig. 1. Isso significa que essa partícula será capaz de arrancar elétrons presentes nos átomos do vapor de álcool ao longo do caminho percorrido por ela, deixando estes átomos positivamente carregados ${ }^{[9]}$. O processo descrito na câmara de nuvens é uma versão atômica dos rastros de cristais de gelo deixados no céu pelos aviões a jato ${ }^{[11]}$.

\section{Utilizando a câmara de nuvens na sala de aula: uma abordagem que integra Física Clássica e Física Moderna}

Como em muitos artigos já se falou na importância da inserção da Física Moderna e Contemporânea no Ensino Médio não me aterei a estes comentários ${ }^{[12,13,14,15,16,17]}$. O objetivo deste artigo é de propor uma atividade que integre a Física Clássica com a Física Moderna e Contemporânea na sala de aula do Ensino Médio.

Certamente, a presença de uma câmara de nuvens atrai a atenção dos estudantes. De um modo geral, assuntos relacionados à Física Moderna e Contemporânea costumam motivar estudantes e professores $^{[18,19,20]}$. Além disso, assuntos ligados a Física Moderna e Contemporânea também são bons temas para discutir a desmistificação do trabalho científico. Segundo Gil et $a l^{[21]}$, os temas citados são muito apropriados para se combater a imagem linear e cumulativa da ciência, tão divulgada em assuntos tratados na Física Clássica. Siqueira e Pietrocola $^{[22]}$, também apresentam temas contemporâneos, em especial as partículas elementares, como importantes motivadores para uma mudança na visão de mundo dos estudantes, possibilitando que esses rompam com o senso comum e assim, sintam-se instigados a interessar-se por conceitos que escapam aos seus sentidos.

A proposta de trabalho com esse equipamento não precisa ser "engessada" ao tradicional currículo do Ensino Médio. Assim, acredita-se que é possível propor uma atividade com o uso da câmara de nuvens em qualquer um dos anos que compõe o Ensino Médio, e também para os anos finais do Ensino Fundamental. O professor pode trabalhar todos os temas sugeridos, mas com níveis de aprofundamento diferentes para os níveis de ensino citados.

Ao planejar para o Ensino Fundamental não é necessário a preocupação de compreensão completa dos temas tratados por parte dos alunos. O mais importante é proporcionar um primeiro contato com estes temas, que, provavelmente, serão retomados no Ensino Médio.

Quanto ao Ensino Médio, acredita-se que apresentar a diversidade dos conceitos abordados, sem a tradicional separação com a qual a Física é apresentada aos estudantes é fundamental para a sua efetiva compreensão. Com esse viés, é possível viabilizar dois conceitos ambicionados para o Ensino de Física: a contextualização e a interdisciplinaridade. Ao apresentarmos assuntos atuais, contextualizamos o aprendizado do aluno no mundo em que ele está inserido e ao mesmo tempo temos a oportunidade de apresentar as inter-relações presentes no tema discutido.

As áreas do conhecimento não podem ser consideradas domínios isolados. Todos os temas abordados em um currículo escolar, naturalmente, contemplam as dimensões de linguagem e o conteúdo humano-social. Sendo assim, apresentar a diversidade do trabalho científico 
é apresentar a sua interdisciplinaridade natural, pois a ciência é interdisciplinar. Assim como contextualizar o tema tratado é fundamental para uma compreensão efetiva do seu significado, desde o desenvolvimento de suas ideias iniciais, até a tecnologia que foi capaz de gerar e o seu impacto na sociedade ${ }^{[23]}$.

A contextualização e a interdisciplinaridade ajudam o aluno a compreender a relevância prática e a universalidade da Ciência. Para isso utilizar elementos vivenciais e cotidianos dos estudantes facilita uma aprendizagem significativa dos temas tratados.

Dessa forma, sugere-se a introdução de atividades motivadoras e desafiadoras, que envolvam a mobilização de recursos cognitivos por parte dos estudantes, promovendo o estabelecimento de conexões entre os conceitos propostos e suas aplicações tecnológicas ${ }^{[23]}$.

Ao apresentar a câmara de nuvens é possível discutir conceitos da Física Clássica como as mudanças de estados físicos da matéria, relações entre variação de temperatura, energia e mudanças de fase, além de processos de transferência de calor. Todos esses temas podem ser abordados durante a explicação sobre o funcionamento da câmara. Quanto aos temas de Física Moderna e Contemporânea, sugere-se: radiações ionizantes, raios cósmicos e radiação natural; partículas elementares e seus métodos de detecção; todos eles podem ser discutidos ao se analisar o que é possível ser detectado com a câmara de nuvens. Em especial, destaca-se a importância do estudo das radiações, tema muito importante a extremante atual, que abrange possíveis vivências de alunos de todas as regiões do nosso país.

No presente artigo a câmara de nuvens foi incorporada a uma unidade de aprendizagem sobre partículas elementares e interações fundamentais ${ }^{[24]}$. Essa unidade de aprendizagem foi elaborada em 2009 e desde então vem sendo aplicada e constantemente atualizada. A unidade de aprendizagem foi incorporada ao currículo da disciplina de Física nas discussões referentes à Eletrostática, em especial ao tema estrutura atômica. Nessa atividade, inicialmente, por meio de uma abordagem histórica crítica, embasada pela epistemologia de Bache$\operatorname{lard}^{[25]}$, em especial a filosofia do não, os alunos discutem a evolução do conceito de átomo e a elaboração dos modelos atômicos ao longo dos séculos. Estas discussões também são divididas com a disciplina de Química. Dentre os temas tratados, procura-se discutir como o cientista "vê" uma partícula elementar e a presença da câmara de nuvens enriqueceu ainda mais a unidade de aprendizagem. Por meio do uso desse instrumento os alunos conseguiram compreender melhor o que eram os "riscos", como dito por eles em muitas ocasiões, que os físicos usavam para identificar as partículas elementares. Comparando com aplicações anteriores desta unidade de aprendizagem, sem o uso da câmara de nuvens, os alunos que utilizaram a câmara de nuvens demostraram muito mais interesse pelas discussões e apresentaram maior compreensão dos conceitos discutidos. Isso pode ser observado nas atividades desenvolvidas, entre elas a elaboração de mapas conceituais sobre a constituição da matéria, nas perguntas e discussões que ocorreram nas salas de aula.

Nesta etapa da unidade de aprendizagem, procura-se explorar estas discussões epistemológicas proporcionadas pelas observações indiretas, como dito anteriormente, e a evolu- 
ção dos significados de algumas palavras como "elementar" e "átomo". Estas discussões têm como objetivo levar os alunos a identificar as mudanças que a ciência sofre justo com a história da humanidade. Apresentando aos alunos uma ciência construída através dos séculos por homens, tentando desmistificar a visão distorcida de que a ciência foi construída por gênios. Além disso, o aluno também reflete sobre uma ciência dinâmica e colaborativa, como por exemplo, a construção do LHC (Large Hadron Collider) no CERN.

A segunda parte da unidade de aprendizagem procura abordar o modelo padrão, seus constituintes e suas interações. O foco principal é de que o aluno reconheça o modelo padrão como o melhor modelo para explicar a estrutura da matéria atualmente e que ele ainda não está totalmente concluído, retomando a discussões sobre uma ciência dinâmica e colaborativa. Além disso, também é importante que o aluno conclua o Ensino Médio conhecendo todas as interações fundamentais da natureza, e não apenas a interação gravitacional e a eletromagnética. Assim como é importante apresentar as contribuições científicas que o estudo das partículas elementares trouxe para a humanidade, suas relações com outras áreas científicas como a área médica e a Cosmologia, na qual se apresenta novamente a discussão sobre os raios cósmicos, fechando a unidade de aprendizagem com a observação da câmara de nuvens, retomando como "vemos" as partículas elementares, sua presença na nossa vida por meio dos raios cósmicos e o estudo destas partículas por meio de laboratórios como o Observatório Pierre Auger e a $\mathrm{AMS}^{11}$ (Alpha Magnetic Spectrometer) instalado na ISS (sigla em inglês para Estação Espacial Internacional) e com base no CERN.

Durante a montagem e a explicação sobre o funcionamento da câmara de nuvens, foram retomados os temas citados anteriormente: mudanças de estados físicos da matéria, relações entre variação de temperatura, energia e mudanças de fase, além de processos de transferência de calor.

Essa integração proporcionada pela câmara de nuvens reflete a integração entre os conteúdos propostos e, consequentemente, a complexidade da Ciência. $\mathrm{O}$ tema pode instigar o questionamento sobre diversos temas, desde a constituição elementar da matéria até Cosmologia.

Por meio desta atividade, também é possível propiciar ao estudante uma vivência com um número grande de informações, sua realidade no mundo atual, favorecendo o desenvolvimento de habilidades como obter, sintetizar, produzir e difundir informações, como preconiza os Parâmetros Curriculares Nacionais $(\mathrm{PCN})^{[26]}$.

Também é sugerido que a discussão sobre esses temas possa ser acompanhada de comentários embasados na História da Ciência, em que um brasileiro esteve envolvido em descobertas que renderam um prêmio Nobel, além de uma discussão envolvendo a filosofia da ciência, representada, por exemplo, por Gaston Bachelard, em especial com a sua Filosofia do Não, de especial importância ao relacionarmos a Física Clássica e a Física Moderna e Contemporânea. O desenvolvimento de uma atividade crítica baseada na análise da História da

${ }^{11}$ Este espectrômetro procura evidências de antimatéria nos raios cósmicos e de matéria escura. 
Ciência favorece a identificação do papel do homem no desenvolvimento da civilização, assim como a mutabilidade das teorias cientificas e a necessidade da compreensão do contexto histórico para aprimorar a compreensão do desenvolvimento científico. Sugere-se Bachelard, por sua preocupação em unir educação e o desenvolvimento do pensamento científico ${ }^{[3]}$.

\section{Considerações finais}

O presente trabalho apresentou sugestões sobre a utilização de um aparato experimental razoavelmente acessível às escolas de Ensino Médio, públicas e particulares. Foram apresentados os dados de construção e funcionamento da câmara de nuvens, assim como foram identificados temas que compõem o currículo da disciplina de Física da maioria das escolas brasileiras e propostas de discussão sobre a complexidade do instrumento elaborado.

Sabemos que a Física Clássica e a Moderna se complementam, mas será que conseguimos passar essas ideias aos nossos alunos? A atividade proposta apresenta uma possibilidade de integrar estes dois temas e apresentar a sua complementaridade e complexidade.

\section{Agradecimentos}

À Diretoria de Educação Básica Presencial da CAPES, à Sociedade Brasileira de Física (SBF), através da Secretaria para Assuntos de Ensino, que, em parceria com o Centro Brasileiro de Pesquisas Físicas (CBPF) organizaram as atividades no LIP e no CERN; ao Prof. Dr. Nilson Garcia especialmente, responsável pela Escola de Física do CERN; aos integrantes do LIP, principalmente ao prof. Pedro Abreu; a Mikk Storn, coordenador da escola de professores do CERN e demais profissionais envolvidos na atividade.

Agradecimentos aos professores Edilson Torma, Dr. Hélio Takai e Maria Clara Santarelli e, em especial, à prof ${ }^{a}$. Dr ${ }^{a}$. Sayonara Salvador Cabral da Costa, pela leitura criteriosa deste artigo.

\section{Bibliografia}

${ }^{[1]}$ ROSENFELD, R. O Cerne da matéria: a aventura científica que levou à descoberta do bóson de Higgs. São Paulo: Companhia das Letras, 2013. 212 p.

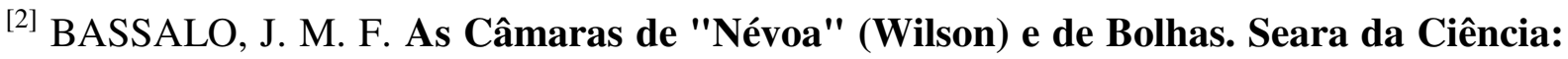
curiosidades da Física. Disponível em: <http://www.seara.ufc.br/folclore/folclore14.htm em 28/02/15>. Acesso em: 28 fev. 2015.

${ }^{[3]}$ PINHEIRO, L. A.; COSTA, S. S. C da; MOREIRA, M. A. Do átomo grego ao Modelo Padrão: os indivisíveis de hoje. Disponível em:

$<$ http://www.if.ufrgs.br/public/tapf/v22_v6_pinheiro_costa_moreira.pdf >. Acesso em: 01 jan. 2014. 
${ }^{[4]}$ CARUSO, F.; OGURI, V. Física Moderna: Origens Clássicas e Fundamentos Quânticos. Rio de Janeiro: Elsevier, 2006. 605 p.

${ }^{[5]}$ SALMERON, R. A. Física Nuclear, raios cósmicos e as origens da física de partículas elementares. In: CARUSO, F.; OGURI, V.; SANTORO, A. (Ed.) 100 anos de Física de Partículas. São Paulo: Livraria da Física, 2005. 338 p.

${ }^{[6]}$ OBSERVATÓRIO PIERRE AUGER. The Pierre Auger Cosmic Ray Observatory. Disponível em: <http://www.auger.org/>. Acesso em: 01 jan. 2014.

${ }^{[7]}$ MARQUES, A. O que são os raios cósmicos? In: CARUSO, F.; OGURI, V.; SANTORO, A. (Ed.). O que são quarks, glúons, bósons de Higgs, buracos negros e outras coisas estranhas? São Paulo: Livraria da Física, 2012. 209 p.

${ }^{[8]}$ BASSALO, J. M. F. O que os físicos brasileiros fizeram em física de partículas? In: CARUSO, F.; OGURI, V.; SANTORO, A. (Ed.). O que são quarks, glúons, bósons de Higgs, buracos negros e outras coisas estranhas? São Paulo: Livraria da Física, 2012, 209 p.

${ }^{[9]}$ CERN: Portuguese Language Teachers Programme 2013. Cloud Chamber Workshop: build your own cloud chamber at home. Disponível em:

$<$ http://teachers.web.cern.ch/teachers/document/cloud-final.pdf>. Acesso em: 01 janeiro 2014.

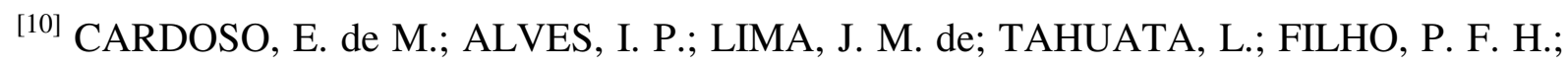
BRAZ, C; PESTANA, S. Radioatividade. Disponível em:

<http://www.cnen.gov.br/ensino/apostilas/radio.pdf>. Acesso em: 01 jan. 2014.

${ }^{[11]}$ HEWITT, P.G. Física Conceitual. Porto Alegre: Bookman, 2011. 743 p.

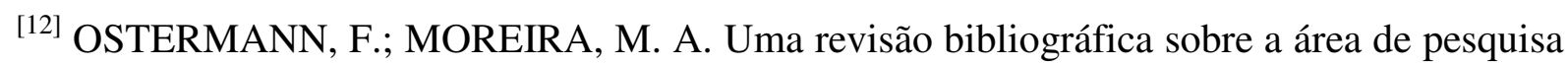
"Física Moderna e Contemporânea no Ensino Médio". Investigação em Ensino de Ciências, Porto Alegre, v. 5, n. 1, janeiro 2000, p. 23-48. Disponível em:

$<$ http://www.if.ufrgs.br/ienci/artigos/Artigo_ID57/v5_n1_a2000.pdf>. Acesso em: 1 jan. 2014.

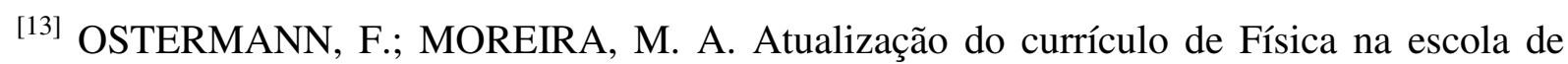
nível médio: um estudo dessa problemática na perspectiva de uma experiência em sala de aula e da formação inicial de professores. Caderno Catarinense de Ensino de Física, Florianópolis, v. 18, n. 2, agosto 2001, p. 135-151. Disponível em:

<https://periodicos.ufsc.br/index.php/fisica/article/view/6676>. Acesso em: 01 jan 2014.

${ }^{\text {[14] }}$ OSTERMANN, F.; CAVALCANTI, C. J. H. Um pôster para ensinar Física de Partículas na escola. Física na Escola, São Paulo, v. 2, n. 1, maio 2001, p. 13-19. Disponível em: <http://www.sbfisica.org.br/fne/Vol2/Num1/particulas.pdf>. Acesso em: 03 jan. 2014. 
${ }^{[15]}$ MOREIRA, M. A. Partículas e interações. Física na Escola, São Paulo, v. 5, n. 2, outubro 2004, p. 10-14. Disponível em: <http://www.sbfisica.org.br/fne/Vol5/Num2/v5n1a03.pdf>. Acesso em: 5 jan. 2014.

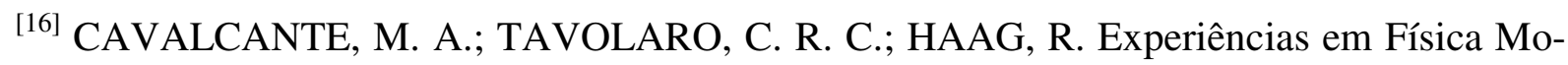
derna. Física na Escola, São Paulo, v. 6, n. 1, p. 75-82, mai. 2005.

${ }^{[17]}$ OLIVEIRA, F. F.,; VIANNA, D. M.; GERBASSI, R. S. Física Moderna no Ensino Médio: o que dizem os professores? Revista Brasileira de Ensino de Física, São Paulo, v. 29, n. 3, setembro 2007, p. 447-454. Disponível em:

<http://www.sbfisica.org.br/rbef/pdf/061108.pdf>. Acesso em: 5 jan. 2014.

[18] WILSON, B. Particle physics at A-level - a theacher's viewpoint. Apud OSTERMANN; MOREIRA, 2000.

${ }^{[19]}$ VALADARES, E. C.; MOREIRA, A. M. Ensinando física moderna no ensino médio: efeito fotoelétrico, laser e emissão de corpo negro. Caderno Brasileiro de Ensino de Física, v. 21, p. 359-371, 2004.

[20] STANNARD, R. Modern physics for the young. Apud OSTERMANN; MOREIRA, 2000 .

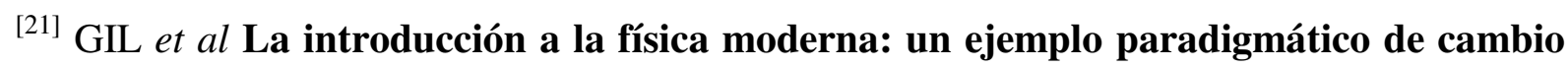
conceptual. Apud OSTERMANN, MOREIRA, 2000.

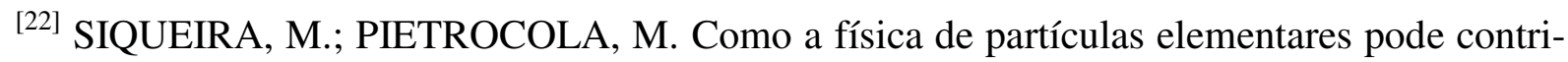
buir no ensino básico? In: CARUSO, F.; OGURI, V.; SANTORO, A. (Ed.). O que são quarks, glúons, bósons de Higgs, buracos negros e outras coisas estranhas? São Paulo: Livraria da Física, 2012. 209 p.

${ }^{\text {[23] }}$ KAWAMURA, M. R. D.; HOSOUME, Y. A contribuição da Física para um novo Ensino Médio. Física na Escola, São Paulo, v. 4, n. 2, p. 22-27, nov. 2003.

${ }^{[24]}$ PINHEIRO, L. A. Partículas elementares e interações fundamentais no Ensino Médio. Dissertação (Mestrado) - Porto Alegre, 2011. Disponível em:

$<$ http://www.lume.ufrgs.br/bitstream/handle/10183/49342/000836027.pdf?sequence=1>. Acesso em: 03 abr. 2015.

${ }^{[25]}$ BACHELARD, G. A filosofia do não. Lisboa: Editoral Presença, 1991. 136 p.

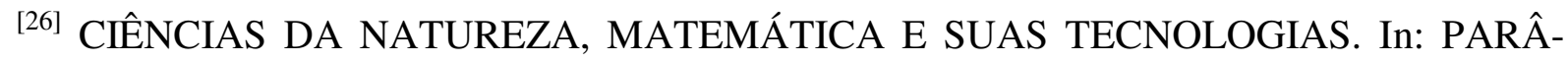
METROS CURRICULARES DO ENSINO MÉDIO. Brasília, 1999. Disponível em: $<$ http://portal.mec.gov.br/seb/arquivos/pdf/ciencian.pdf>. Acesso em: 6 jan. 2014. 